\title{
CHART FOR DETERMINING THE SPHAERODACTYLS OF THE PORTO RICO REGION
}

\author{
Chapman Grant, Major, United States Army
}

It is hoped that the reader has seen the paper by the same author describing five new Sphaerodactyls and reestablishing another in the July number of this Journal as this chart is for the ready determination of these and the new species described in this number of the Journal. Altogether there are eight species now known from this region.

I find that a key has an objectionable feature because a decision must frequently be made on a matter of opinion or definition. A reader unfamiliar with a group may be led astray by a wrong choice while using a key. In the present chart any specimen may be referred to any of the thirteen columns. There is no necessity for starting over as is necessary with a key, because if one column leads to an impasse with a certain specimen, the student may ignore that character and run down one of the other columns.

In making an identification it is advisable first to determine the sex of the specimen. It will be noted that three of the eight species have sexual dichromatism. Sex determination immediately narrows the field.

Sex determination is easy in this genus. Examine the belly scales with a hand lenz. The male has a chevron shaped patch of noticeably flat or slightly concaved and usually lighter colored scales anterior to the vent. The branches of the chevron extend onto the hind legs. The scales of this part of the female are not differentiated. See Plate XX. July number of this Journal.

Use of the Chart. Explanation of Terms.

In Column 6, the "cross" on the head of S. monensis is more or less a matter of opinion. I will gladly adopt a more comprehensive term. The advantage of the term "cross" is that there are various types of erosses. There are also various designs on the head of $S$. monensis.

"The target" is an oval occipital spot encircled by an oval ring, usually of the same color.

Columns 7 and 8 . The species of this group have a dark line or the vestiges of one, beginning at the eye and extending backwards for various distances according to the species. This line is bordered 
above by a lighter line, also extending variously according to the species.

Column 9. 'The "chin" bears a pattern that is quite specific in certain forms. By "chin" is meant the area from the mental to a line joining the bulbs of the lower jaw. Some might call it the "throat".

Columa 10. The "scapular pattern" is a feature of this genus. It is best shown in 8 . grandisquamis. In this species it usually consists of a black blotch across the shoulders, outlined by white and bearing two white dots. The resemblance to a mask is striking. "Spectacle" is suggested by Dr. Barbour for the scapular pattern when it tends to change from a mask to two little tangent targets.

Column 11. The "sacral pattern" is second only to the seapular pattern in this genus. Usually it is most conspicuous at the region of the sacrum, but is frequently repeated several times along the tail. Generally it is formed by a continuation or reappearance of the ocular white line and the outermost dorsal dark line or line of dots which is intensified at this point. T'he form and degree of this pattern is specific.

Columns 9, 12 and 13. Keels: It is very difficult to determine whether or not certain seales are keeled in these species. It is neeessary to let the specimen become slightly dry and to sean it with a hand lenz in a mild light that comes from the side. A bright light or a direct light, moisture or too high magnifieation make the keeis almost invisible.

Notes to Sphaerodactyl Chart.

1. Fades in aleohol.

2. The Culebra form only is covered in this chart. The form from Vieques is eovered by these notes where it differs from the Culebra form and is referred to by the letter " $\mathrm{V}$ ". The Culebra form is referred to by the letter " $O$ ".

3. Red head. The $\mathrm{C}$ has a plain red head above in 22 per' cent of the males; with no intermediate forms with the speckle head males. The $V$ has a larger per cent of red head males and the red continues underneath the head as red or orange. Some have a dark occipital spot on the red head and some have spotted or marbled chins, whereas $C$ invariably has a white chin and no occipital spot.

4. Brown. The $\mathrm{V}$ is much darker brown than $\mathrm{C}$.

5. V males, not the red heads, have regular "target" or mottled head.

6. See Note 3.

7. In $V$ this line is much clarker, nearly black. 


\begin{tabular}{|c|c|c|c|c|c|}
\hline & & & & & \\
\hline & & & & i & \\
\hline & & & & & \\
\hline 咅 & 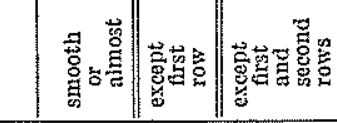 & & 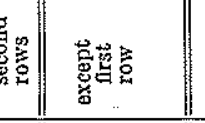 & 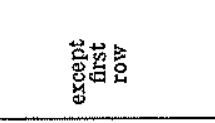 & 焉 \\
\hline & $\frac{1111}{1 \|}$ & & $\frac{1}{1}$ & $\frac{1}{1}$ & + \\
\hline & +11 & $+1+$ & $1+$ & + & \\
\hline & & & 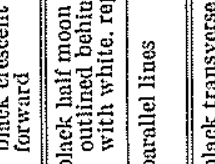 & & \\
\hline 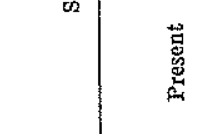 & 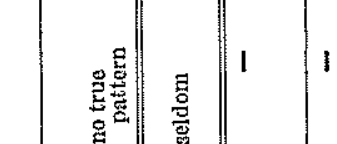 & & $\mid$ & & 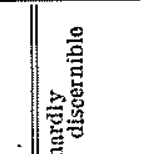 \\
\hline & & & $\mid$ & 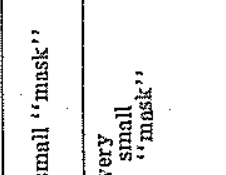 & \\
\hline 1 & $1 \|$ & 1 & $\mid \frac{1}{11}$ & 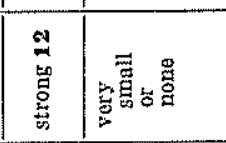 & $\mid$ \\
\hline & 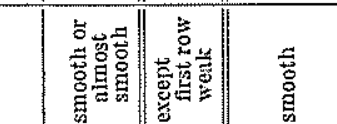 & 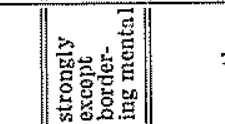 & 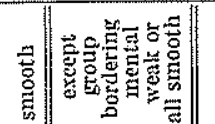 & 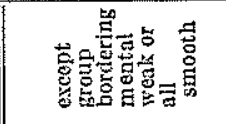 & 墨 \\
\hline & \begin{tabular}{l||l|l} 
& $\frac{9}{3}$ \\
\end{tabular} & 11 & | & 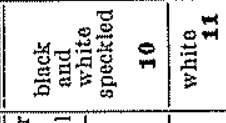 & 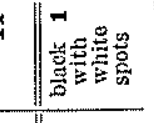 \\
\hline 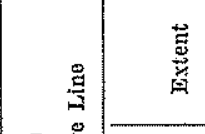 & 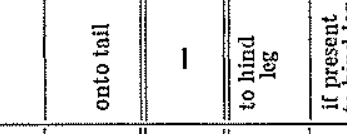 & 童 & 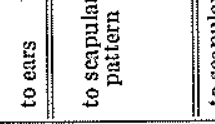 & 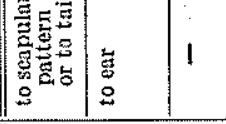 & $1 \frac{1}{10}$ \\
\hline 童 & 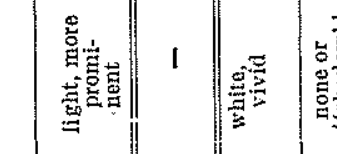 & 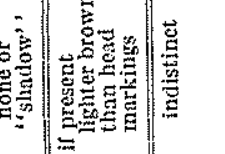 & 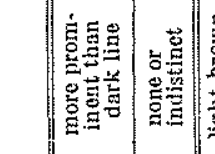 & 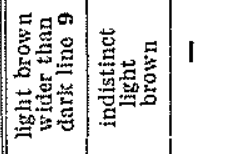 & 箸 \\
\hline & 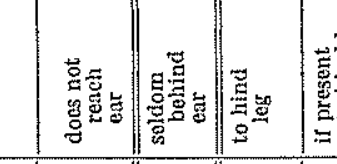 & 童 & 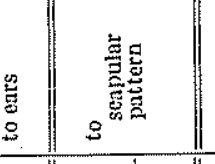 & $\mid$ & $e^{a^{2}}$ \\
\hline 童高 & 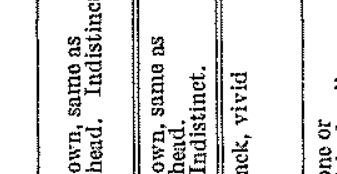 & 部 & 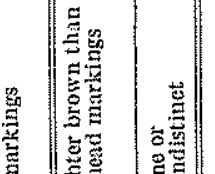 & 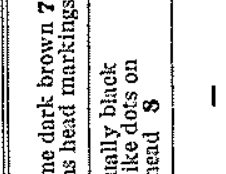 & 1 \\
\hline 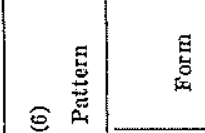 & 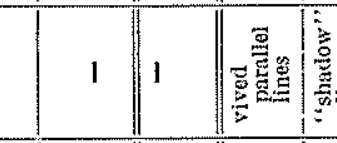 & & in & 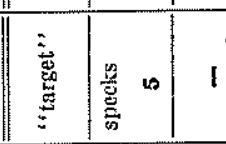 & i \\
\hline 1 & $\begin{array}{ll}1 & 1 \\
\end{array}$ & 1.4 & $\mid$ & 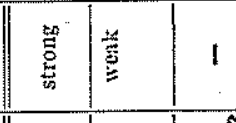 & \\
\hline 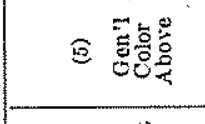 & 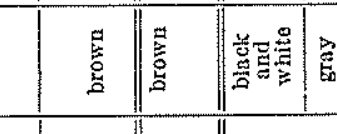 & 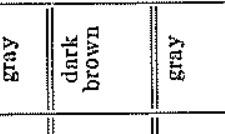 & 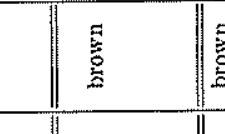 & 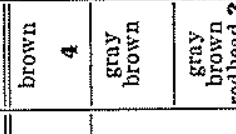 & \\
\hline 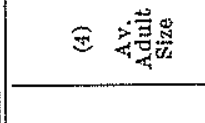 & \begin{tabular}{ll|l}
8 & $=8$
\end{tabular} & 10 & 8 & 8 & \\
\hline 8 & 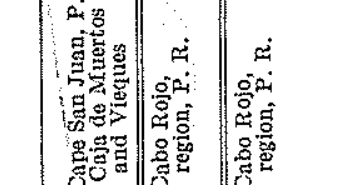 & 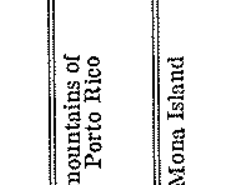 & $\frac{2}{2}$ & 1 & 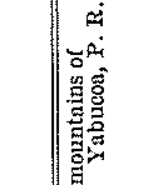 \\
\hline 酷 & \begin{tabular}{l|l|l|l|l|l} 
& 1 & 1 \\
\end{tabular} & 11 & 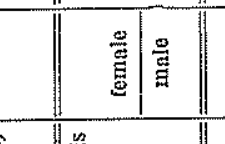 & 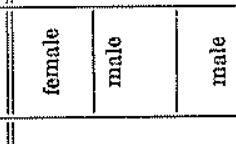 & i. \\
\hline 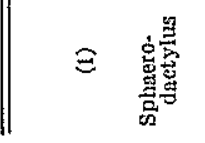 & 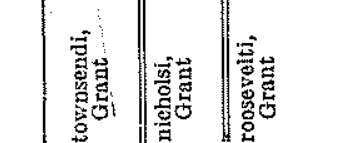 & $\mid$ & & & 能 \\
\hline
\end{tabular}


8. V males have the dark eye line a light brown instead of "black'.

9. White in $\mathrm{V}$.

10. In $V$, gray or black and white speckled or striped.

11. In $V$, orange or white or gray or mottled. The orange fades in alcohol.

12. In $\mathrm{V}$, reduced or wanting.

13. In V, usual.

14. In $V$, same pattern, but repeated several times onto tail. 